\title{
EFFECT OF THE AEROBIC COMPONENT OF COMBINED TRAINING ON THE BLOOD PRESSURE OF HYPERTENSIVE ELDERLY WOMEN
}

\author{
EFEITO DO COMPONENTE AERÓBICO NO TREINAMENTO COMBINADO SOBREA PRESSÃO ARTERIAL \\ DEIDOSAS HIPERTENSAS
}

\author{
EFECTO DEL COMPONENTE AERÓBICO EN EL ENTRENAMIENTO COMBINADO SOBRE LA PRESIÓN \\ ARTERIAL DE MUJERES DE TERCERA EDAD HIPERTENSAS
}

Magno Petrônio Galvão Leandro 1,2 (Physical Education Professional)

José Luiz Silva de Moura, ${ }^{1,2}$

(Physical Education Professional)

Gustavo Willames Pimentel Barros? (Physical Education Professional)

Adilson Pereira da Silva Filho 1,2

(Physical Education Professional)

Aline Cavalcante de Oliveira Farias' (Nutritionist)

Paulo Roberto Cavalcanti

Carvalho 1,2,3

(Physical Education Professional and Biologist)

1. Universidade Federal de Pernambuco, Centro de Ciências da Saúde, Department of Physical Education, Laboratório de Análises Biológicas do Exercício Físico, Recife, PE, Brazil.

2. Physical Education Graduate Studies Program, Universidade Federal de Pernambuco, Recife, PE, Brazil.

3. Universidade Federal de Pernambuco, Hospital das Clínicas, Unidade de Serviço de Promoção da Saúde e Qualidade de Vida, Recife, PE, Brazil.

\section{Correspondence:}

Paulo Roberto Cavalcanti Carvalho. Av. Professor Moraes Rêgo, 1235, Cidade Universitária, Recife, PE, Brazil. 50670420

paulo.robertocarvalho@ufpe.br

\begin{abstract}
Introduction: Aerobic (AT), strength (ST) and combined (CT) training are already well referenced as a method for the treatment and control of arterial hypertension (AH) inducing positive changes in blood pressure (BP) reduction, a phenomenon known as post-exercise hypotension (PEH). However, the correct order of combined training to promote PEH is still unclear. Objective: To verify the effect of the order of the aerobic component in combined training on PEH among hypertensive elderly women. Methods: Randomized clinical trial of 24 elderly hypertensive women allocated to three training groups: Group 1 - Aerobic + Strength Training (AT + ST), Group 2 - Strength + Aerobic Training (ST + AT) and Group 3 - Aerobic + Strength + Aerobic Training (AT + ST + AT). Participants underwent AT at $60 \%$ heart rate reserve intensity for 30 minutes and ST with four exercises in three sets of 12 repetitions at $60 \%$ of one-repetition maximum (1RM) also for 30 minutes. The training involved 24 sessions (three times a week).Systolic (SBP) and diastolic blood pressure (DBP) were measured in all groups at time points before and after each session, and the mean BP (MBP) was calculated. Results: The variables analyzed did not differ significantly between groups in either the pre- or post-training period. MBP showed a significant reduction only in G1. However, G3 had a greater effect on all the variables analyzed. Conclusion: Combined training with an aerobic component (G3) generated a significant post-exercise hypotensive effect over 24 sessions, and is indicated for elderly hypertensive women. Level of evidence Il; Therapeutic studies.
\end{abstract}

Keywords: Aging; Hypertension; Aerobic exercise; Resistance training.

\section{RESUMO}

Introdução: O treinamento aeróbico (TA), de força (TF) e combinado (TC) já são bem conhecidos como método de tratamento e controle da hipertensão arterial (HA), levando a alterações positivas na redução da pressão arterial (PA), fenômeno denominado hipotensão pós-exercício (HPE). Porém, persistem dúvidas quanto à ordem do treinamento combinado para promoção da HPE. Objetivo: Verificar o efeito da ordem do componente aeróbico no treinamento combinado na HPE em idosas hipertensas. Métodos: Ensaio clínico randomizado composto por 24 idosas hipertensas, distribuídas em três grupos de treinamento: Grupo 1 - Treinamento Aeróbico + Força (TA+TF), Grupo 2 - Treinamento de Força + Aeróbico (TF+TA) e Grupo 3 - Treinamento Aeróbico + Força + Aeróbico (TA+TF+TA). As participantes foram submetidas ao TA com intensidade de $60 \%$ da frequência cardiaca de reserva durante 30 minutos e ao TF com quatro exercícios, em três séries de 12 repetições, a 60\% de uma repetição máxima (1RM) também de 30 minutos. Os treinamentos foram realizados ao longo de 24 sessões (três vezes por semana), sendo aferidas a pressão arterial sistólica (PAS) e diastólica (PAD) em todos os grupos, nos períodos antes e após cada sessão, e calculada a PA média (PAM). Resultados: As variáveis analisadas não diferiram significativamente entre os grupos, nem no período pré-, nem no pós-treino. A PAM apresentou redução significativa apenas no G1. Porém, o G3 teve efeito maior sobre todas as variáveis analisadas. Conclusão: O treinamento combinado com aeróbico fracionado (G3) gerou grande efeito hipotensor pós-exercício ao longo das 24 sessões, sendo indicado para o público de idosas hipertensas. Nível de evidência ll; Estudos terapêuticos.

Descritores: Envelhecimento; Hipertensão; Exercício aeróbico; Treinamento de resistência.

\section{RESUMEN}

Introducción: El entrenamiento aeróbico (EA), de fuerza (EF) y combinado (EC) ya están bien referenciados como forma de tratamiento y control de la hipertensión arterial (HA) llevando a alteraciones positivas en la reducción de la presión arterial (PA), fenómeno denominado hipotensión post-ejercicio (HPE). Sin embargo, persisten dudas cuanto al orden del entrenamiento combinado para promoción de la HPE. Objetivo: Verificar el efecto del orden del componente aeróbico en el entrenamiento conjunto en la HPE de mujeres de tercera edad hipertensas. Métodos: Ensayo clínico aleatorizado compuesto por 24 mujeres de tercera edad hipertensas, distribuidas en tres grupos de entrenamiento: Grupo 1 - Entrenamiento Aeróbico + Fuerza (EA+EF), Grupo 2-Entrenamiento de Fuerza + Aeróbico (EF+EA) y Grupo 3-Entrenamiento Aeróbico + Fuerza + Aeróbico 
(EA+EF+EA). Las participantes fueron sometidas al EA con intensidad del 60\% de la frecuencia cardíaca de reserva durante 30 minutos y al EF con cuatro ejercicios, en tres series de 12 repeticiones, al 60\% de una repetición máxima (1RM) también de 30 minutos. Los entrenamientos fueron realizados a lo largo de 24 sesiones (tres veces por semana), siendo medidas la presión arterial sistólica (PAS) y diastólica (PAD) en todos los grupos, en los períodos antes y después de cada sesión, y se calculó la PA media (PAM). Resultados: Las variables analizadas no difirieron significativamente entrelos grupos, nien el momento pre, ni post entrenamiento. La PAM presentó reducción significativa sólo en el G1. Sin embargo, el G3 tuvo efecto mayor sobre todas las variables analizadas. Conclusión: El entrenamiento combinado con aeróbico fraccionado (G3) generó gran efecto hipotensor post ejercicio a lo largo de 24 sesiones, siendo indicado para el público de mujeres de tercera edad hipertensas.

Nivel de evidencia ll; Estudios terapéuticos.

Descriptores: Envejecimiento; Hipertensión; Ejercicio aeróbico; Entrenamiento de resistencia.

\section{INTRODUCTION}

Arterial hypertension (AH) can be defined as a syndrome of multifactorial and multicausal origin with characteristics such as increased and sustained blood pressure values and other metabolic conditions. ${ }^{1}$ The prevention and non-drug treatment of $\mathrm{AH}$ consists of changes in lifestyle, including physical exercise, to control blood pressure levels. ${ }^{2}$

Physical exercise can contribute to a reduction in blood pressure (BP) ${ }^{3}$ by generating a temporary decrease in tension, even after a single exercise session, due to the phenomenon called post-exercise hypotension (PEH). ${ }^{4}$ According to Bermudes et al., ${ }^{5}$ factors such as intensity, duration, and type of exercise performed, along with resting blood pressure levels, may influence the amplitude and duration of PEH, allowing different responses in the cardiovascular system, significantly modifying the BP in the acute, subacute, and chronic post-exercise effects. ${ }^{6}$

Aerobic training (AT) and strength training (ST) promote significant


ding to Sharman and Stowasser, ${ }_{1}^{8}$ AT causes important autonomic and hemodynamic changes that can act on the cardiovascular system, preserving cellular homeostasis in the event of an increase in metabolic demands promoted by hypertension. These same authors also reported that resistance training, as well as AT, improves hypotensive results.

According to Vieira and Queiroz, ${ }^{9}$ despite the differences between ST protocols for hypertensive elderly patients, such training provided a reduction in resting BP in approximately $94 \%$ of the studies analyzed. This influence of ST on vascular behavior is mainly related to an improvement in cardiac functional capacity, in which there is an increase in ejection volume and a decrease in cardiac output and heart rate, in addition to double product reduction. In the long term, these hemodynamic changes will decrease peripheral vascular resistance through vasodilator substances, as well as blood pressure, as it is already clear from the literature that the major factor for hypertension is peripheral vascular resistance. ${ }^{10}$

The combination of AT and ST in the same session, defined as combined training (CT), ${ }^{11}$ has been used as an alternative for the improvement of cardiac blood pressure variables in adult and elderly men and women. ${ }^{12}$ According to Corso et al. ${ }^{13}{ }^{13} \mathrm{CT}$ can be a strategy for the reduction of blood pressure in hypertensive elderly patients. Further comparative studies are needed to understand the training sequence and its contributions to the control and treatment of BP abnormalities in this population. Thus, the present study aims to verify the effect of the order of the CT on PEH in elderly hypertensive women.

\section{METHODS}

\section{Sample and Experimental Design}

This clinical trial's protocol was approved by the Ethics Committee on Research with Human Beings of the Health Sciences Center of the Federal University of Pernambuco (CEP/CCS/UFPE), under number CAAE-02990.172.000-11.
Twenty-four elderly hypertensive women ( $64.03 \pm 0.19$ years of age) were selected, based on the diagnosis, who were physically active and had no musculoskeletal or cognitive limitations or any other disease that could prevent the execution or continuity of the training. The elderly women were not engaged in other exercise programs during the research intervention. All elderly women used only thiazide diuretics, calcium channel blockers (dihydropyridines), and angiotensin II receptor antagonists. However, the control of the drugs were not homogenous. Elderly hypertensive women who used beta-blockers, which affect cardiovascular response, and thus, would hinder the interpretation of data and the use of heart rate for the prescription of training, were excluded.

All women were informed about every procedure used and agreed voluntarily by signing the informed consent form. Three treatment groups were formed: Group 1 - aerobic/strength training (AST), Group 2 - strength/aerobic training (SAT), and Group 3 - aerobic/strength/aerobic training (ASAT), where the distribution in the groups was determined using random allocation (the order of arrival).

\section{Questionnaires and Anthropometric Assessments}

The elderly women responded to an anamnesis, with personal information (i.e., name; age; race; and health, nutritional, and orthopedic history). Anthropometric data such as body mass, height, and skin fold thickness, measured with the aid of a scale with a coupled stadiometer (Welmy W110H LED display) and a CESCORF scientific adipometer, using the Siri calculation of body density ${ }^{14}$ and the Jackson and Pollock fat percentage protocol, ${ }^{15}$ were evaluated.

\section{Hemodynamic Variables Measurements}

During the auscultatory intervention, BP measurements were taken five minutes before and after each training session.

\section{Cardiorespiratory Test}

Cardiorespiratory parameters were obtained through the submaximal exercise stress test (EST), and a prior orientation was provided asking the participants to not perform any other physical exercises or suspend any drugs related to BP control. In addition, the consumption of stimulants such as soda, coffee, and tea was prohibited. Participants were also instructed to have a light meal two to three hours prior to EST. Furthermore, the Santos protocol, ${ }^{16}$ adapted to use a treadmill (the protocol originally suggested a cycle ergometer), was used, employing the method validated by Swain et al. ${ }^{17}$ and the ACSM metabolic equation ${ }^{18}$ for running.

\section{One-repetition maximum test (1RM)}

Strength protocols were performed on two separate days, with a 48-hour interval between them. On the first day, the vertical bench press and leg press tests were performed, and on the other day, the rowing and extender tests were performed. The protocol used was given by the 
American College of Sports Medicine (ACSM), ${ }^{19}$ which initially consisted of a warm-up with ten repetitions of a light load; after five minutes, 1RM load tests were performed. Five attempts were assessed for each exercise, with an interval of five minutes between each, taking into account the largest load used for a complete repetition by the individual.

\section{Intervention Procedures}

The elderly women were evaluated at baseline (pre-) and at the end of eight weeks of training (post-). All data collection was performed at the Department of Physical Education at the Professor José César de Albuquerque Farias Laboratory Complex.

The intervention consisted of 24 training sessions, with a frequency of three weekly sessions (Mondays, Wednesdays, and Fridays). In all sessions, SBP and DBP at rest were measured five minutes before the exercise and at the end of each session after the participants had remained in post-exercise recovery in a sitting position for five minutes.

In the AT protocol, the sessions consisted of 30 minutes of walking at $60 \%$ of the resting pulse rate (RPR) monitored using a frequency meter $\left(\right.$ Polar $^{\circledR}$, model FT7) on a treadmill. ${ }^{20}$

The ET protocol lasted 30 minutes and consisted of four exercises (horizontal leg press, low row, extensor chair, and seated machine bench press). Three sets of 12 repetitions at $60 \%$ of 1 RM were performed with a 90-second rest between sets and 120 seconds between exercises. ${ }^{21}$ All groups were monitored using an adapted Borg scale.22 The three training groups were allocated as follows:

\section{Group 1 - aerobic/strength training (AST)}

Sessions began with aerobic training, with 30 minutes of continuous walking at $60 \%$ of RPR; then four exercises were performed (horizontal leg press, low row, chair, and seated machine bench press), with three sets of 12 repetitions at $60 \%$ of 1 RM, a 90 -second rest between sets, and 120 seconds between exercises (lasting 30 minutes).

\section{Group 2 - strength/aerobic training (SAT)}

The sessions started with strength training with four exercises (horizontal leg press, low row, extensor chair, seated machine bench press) performed in three sets of $1260 \% 1$ RM repetitions with a 90-second rest between sets and 120 seconds between exercises (with an average duration of 30 minutes), immediately followed by 30 continuous minutes of walking at $60 \%$ of RPR.

\section{Group 3 - aerobic/strength/aerobic training (ASAT)}

The sessions started with aerobic training with 15 minutes of running at the same intensity described previously, followed by the strength training, and ending with another 15 minutes of continuous walking.

\section{Statistical analysis}

For the variables of systolic, diastolic, and mean blood pressure, the Shapiro-Wilk normality test was used and, subsequently, the t-test ( $p \leq$ 0.05) was performed for paired samples to detect possible differences between pre- and post-training evaluation, after stratification in the training groups. Effect size (ES) analysis between pre- and post-training time in the different groups was performed using Cohen's $d_{m}$ index for paired samples, ${ }^{23}$ with the following interpretations: $<0.19$ not significant; 0.20-0.49 small; 0.50-0.79 medium; 0.80-1.29 large; and >1.3 very large.

For comparison between the groups, the variables were submitted to analysis of variance (ANOVA) and the means compared by the Tukey test with a 5\% significance level. The root mean square standardized effect (RMSSE) index, in accordance with Steiger and Fouladi (2016), was calculated. ${ }^{24}$ The interpretations of the indices obtained were performed according to Cohen's scale (1988), ${ }^{23}$ as above. The software used for analysis was Statistical Package for Social Sciences v.23.

\section{RESULTS}

Initially, 30 hypertensive elderly women were selected. However, six individuals were excluded, two for not attending the training sessions and four due to illness. Adherence among the other participants in the program was high (>95\%).

Table 1 presents the characteristics of the participants as mean and standard deviation. When analyzing the BMI and \% fat, we noted that all the elderly persons evaluated were overweight; however, they were classified as having good cardiorespiratory capacity.

Table 2 presents the results of the comparison of hemodynamic variables of the hypertensive elderly women after 24 training sessions. There was no significant difference in hemodynamic variables in any of the groups when comparing the pre- and post-training parameters, except for $\mathrm{MBP}$ in $\mathrm{G} 1$ presenting a reduction of $10.8 \mathrm{mmHg}$. All parameters of G3 were reduced at $18.84 \mathrm{mmHg}, 17.80 \mathrm{mmHg}$, and $14.96 \mathrm{mmHg}$ for $\mathrm{SBP}, \mathrm{DBP}$, and MBP, respectively. This variation observed in G3 was also consistent with the large effect size in this group between pre- and post-training for all variables analyzed.

Table 1. Characteristics of the elderly women evaluated by group.

\begin{tabular}{c|c|c|c}
\hline \multirow{2}{*}{ Variables } & G1 & G2 & G3 \\
\cline { 2 - 4 } & M (SD) & M (SD) & M (SD) \\
\hline Age & $66.26(5.12)$ & $63.10(3.02)$ & $61.31(3.24)$ \\
\hline Body mass $(\mathrm{kg})$ & $65.76(3.49)$ & $62.38(8.32)$ & $70.30(7.57)$ \\
\hline Height $(\mathrm{m})$ & $1.60(0.02)$ & $1.61(0.04)$ & $1.59(0.03)$ \\
\hline $\mathrm{BMl}\left(\mathrm{kg} / \mathrm{m}^{2}\right)$ & $25.27(2.24)$ & $26.44(0.07)$ & $28.07(1.60)$ \\
\hline$\%$ Fat & $28.16(0.55)$ & $26.02(4.87)$ & $28.40(7.41)$ \\
\hline $\mathrm{VO}_{2} \mathrm{max}(\mathrm{mL} / \mathrm{kg} / \mathrm{min})$ & $39.00(7.08)$ & $38.22(4.55)$ & $40.40(3.71)$ \\
\hline $\mathrm{RPR}(\mathrm{bpm})$ & $70.60(7.63)$ & $60.50(5.51)$ & $71.16(4.81)$ \\
\hline
\end{tabular}

G1-aerobic/strength training (AST); G2 - strength/aerobic training (SAT); G3-aerobic/strength/aerobic training (ASAT); $\mathrm{BMI}=$ body mass index; $\% \mathrm{fat}=$ percentage of body fat; $\mathrm{VO}_{2}$ max = maximum oxygen volume; $\mathrm{RPR}=$ resting pulse rate; $\mathrm{M}=$ mean; $\mathrm{SD}=$ standard deviation

Table 2. Comparison of pre- and post-training hemodynamic variables of the three groups of hypertensive elderly women undergoing different training interventions.

\begin{tabular}{|c|c|c|c|c|c|c|}
\hline & & $\begin{array}{c}\text { G1 } \\
\text { (SAT) }\end{array}$ & $\begin{array}{c}\text { G2 } \\
\text { (TSA) }\end{array}$ & $\begin{array}{c}\text { G3 } \\
\text { (ASAT) }\end{array}$ & $p$ & RMSSE \\
\hline \multirow{4}{*}{ 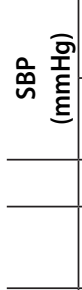 } & pre-workout & $113.80 \pm 7.10$ & $130.40 \pm 23.47$ & $142.96 \pm 20.91$ & 0.16 & $\begin{array}{c}0.820 \\
\text { (large) }\end{array}$ \\
\hline & post- training & $113.40 \pm 4.77$ & $133.40 \pm 7.82$ & $124.12 \pm 9.95$ & 0.24 & $\begin{array}{c}0.845 \\
\text { (large) }\end{array}$ \\
\hline & p & 0.93 & 0.20 & 0.18 & & \\
\hline & Cohen's $d_{m}$ & $\begin{array}{c}0.067 \\
\text { (insignificant) } \\
\end{array}$ & $\begin{array}{c}0.192 \\
\text { (insignificant) } \\
\end{array}$ & $\begin{array}{c}1.221 \\
\text { (large) }\end{array}$ & & \\
\hline \multirow{4}{*}{ 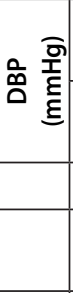 } & pre- workout & $57.40 \pm 14.35$ & $71.00 \pm 7.69$ & $79.48 \pm 19.48$ & 0.27 & $\begin{array}{c}0.662 \\
\text { (medium) }\end{array}$ \\
\hline & post- training & $53.33 \pm 21.83$ & $71.40 \pm 6.50$ & $61.68 \pm 11.07$ & 0.43 & $\begin{array}{c}0.627 \\
\text { (medium) }\end{array}$ \\
\hline & $\mathrm{p}$ & 0.60 & 0.93 & 0.08 & & \\
\hline & Cohen's $d_{m}$ & $\begin{array}{c}0.225 \\
(\text { small) }\end{array}$ & $\begin{array}{c}0.056 \\
\text { (insignificant) }\end{array}$ & $\begin{array}{c}1.165 \\
\text { (large) }\end{array}$ & & \\
\hline \multirow{4}{*}{ 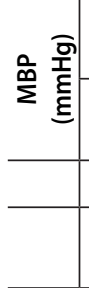 } & pre-workout & $77.33 \pm 12.11$ & $88.30 \pm 11.73$ & $98.40 \pm 15.42$ & 0.19 & $\begin{array}{c}0.771 \\
\text { (medium) }\end{array}$ \\
\hline & post- training & $66.53 \pm 12.46$ & $89.40 \pm 8.76$ & $83.44 \pm 7.92$ & 0.06 & $\begin{array}{c}1.242 \\
\text { (large) }\end{array}$ \\
\hline & $p$ & 0.00 & 0.69 & 0.12 & & \\
\hline & Cohen's $d_{m}$ & $\begin{array}{c}0.879 \\
\text { (large) }\end{array}$ & $\begin{array}{c}0.107 \\
\text { (insignificant) }\end{array}$ & $\begin{array}{c}1.282 \\
\text { (large) }\end{array}$ & & \\
\hline
\end{tabular}

G1 - aerobic/strength training (AST); G2 - strength/aerobic training (SAT); G3 - aerobic/strength/aerobic training $(\mathrm{ASAT}) ; \mathrm{SBP}=$ systolic blood pressure; $\mathrm{DBP}=$ diastolic blood pressure; $\mathrm{MBP}=$ mean blood pressure. The values presented are means followed by the standard deviation analyzed between the pre and post training by $\mathrm{t}$-test $(p \leq 0.05)$ for the same group and ANOVA ( $p \leq 0.05)$ for between-group comparisons. RMSSE (Root Mean Square Standardized Effect) values and Cohen's $\mathrm{d}_{\mathrm{m}}$ values are effect size (ES) indices. 
Through the simultaneous analysis of the groups, it was possible to observe a significant effect on SBP, both before and after training, as well as on the post-training MBP (Table 2). DBP, measured both before and after training, showed a medium effect in the groups analyzed (Table 2).

\section{DISCUSSION}

Through the data obtained in the present study, it was possible to verify the effect of the order of training in $\mathrm{CT}$ on $\mathrm{PEH}$. This is the first study to analyze the effect of a CT intervention in a hypertensive elderly population.

The results of the present study show a significant decrease in MBP in G1. This result corroborates that reported by Santos et al. ${ }^{25}$ who analyzed hypertensive elderly women over the course of 16 weeks. Regarding the SBP and DBP for all groups, there was no significant difference. This is in contrast to other studies that analyzed BP in terms of the acute ${ }^{7}$ and chronic effects of CT?

According to or statistical analysis, regardless of the order of training in CT, no PEH was noted. These results were similar to those reported by Teixeira et al. ${ }^{26}$ and Davitt et al. ${ }^{27}$ In the present study, this can be explained by the small sample size of each group, as well as the lack of homogeneity in drug control. However, these results are not consistent with those of Cadore et al. ${ }^{28}{ }^{28}$ who analyzed normotensive elderly individuals and confirmed that ST should be performed before AT, since this sequence promotes greater neuromuscular adaptation ensuring greater benefits in terms of functional capacity in this population.

Although no significant difference was observed between the groups, effect size analysis showed that G3 showed a substantial effect on all variables assessed when compared to the other groups. These results differ from those of Park et al. ${ }^{29}$ who analyzed prehypertensive individuals who performed walking exercises in a fractional manner (three to four 10-minute sessions with recovery intervals (50-40 minutes total) and continuous exercise (30-40 minutes), with $50 \%$ intensity of $\mathrm{VO}_{2}$ peak. However, these divergent results may be attributable to the different protocols employed in the two studies. These results underscore the importance of analyses taking into account the effects of training, especially on BP parameters, since a reduction by two to three $\mathrm{mmHg}$ in both SBP and DBP may reduce the risk of cardiac complications by up to $20 \%{ }^{30}$ Therefore, it is important to analyze the effect size.

The increase in SBP after ST is mainly due to the increase in cardiac output (CO) promoted by the increase in catecholamines and endothelin during activity. ${ }^{30}$ SBP is of great importance in hypotension, because the higher the SBP values, the higher the hypotensive response. ${ }^{9}$ Dynamic resistance training causes SBP elevation; it however has positive consequences and enables greater adaptations in the PEH effect. Thus, several studies seek to understand the hypotensive effects of resistance training. ${ }^{29}$
AT is also involved in the enhancement of $\mathrm{PEH}$, mainly due to the recruitment of large muscle groups to perform aerobic exercise - which provides improvements in hypotensive responses ${ }^{12}$ associated with cardiorespiratory, vascular, and metabolic changes - since this result is closely related to the reduction in $\mathrm{CO}$ resulting from resting bradycardia. ${ }^{19}$ The use of AT is consistent with certain studies in the literature that demonstrate the significant effect of this training on BP control. ${ }^{20}$

A previous study, evaluating hypertensive subjects undergoing $\mathrm{CT}$, also reported results regarding $\mathrm{PEH}$ in the subjects analyzed, ${ }^{13}$ corroborating the findings of the present study. Thus, after training with varying order of exercises, hypertensive elderly women seem to show PEH. However, there is still no consensus on the appropriate dose-response relationship to ensure better benefits in terms of BP parameters in this population (e.g., relationship between intensity, duration, mode of execution, volume, and muscle mass involved)..$^{10}$ The greater cardiovascular responses noted with aerobic and strength exercises are partly due to peripheral and central mechanisms underlying autonomic modulation, respectively. ${ }^{8}$ In aerobic exercise, a change in sympathetic modulation (decrease in sympathetic tone and increase in parasympathetic tone) as a result of hypertension has been shown to be associated with an exacerbated activation of the sympathetic autonomic system at rest. ${ }^{1}$ In strength exercise, the afferent muscular nerves are stimulated by mechanisms associated with mechanical reflex and metaboreflex controls.

The present study compared between the effects of the order of training (aerobic and strength) on BP parameters in hypertensive elderly women, since the literature on this subject is still scarce. Moreover, based on our findings, it is recommended that AT is split for CT as in $\mathrm{G} 3$ in this study and common practice in training centers. The lack of homogeneity in terms of the number of participants in each group after randomization and drug control are the main limitations of this study and preclude further conclusions about $\mathrm{PEH}$.

\section{CONCLUSION}

The study reinforces the benefits of $\mathrm{CT}$ for hypertensive elderly women, concluding that the use of aerobic and strength training with fractionation of aerobic training over the course of 24 sessions generated a large hypotensive effect after exercise and may be recommended for the elderly hypertensive population. However, further studies in the field of exercise cardiology are suggested to elucidate the underlying physiological mechanisms of this effect.

All authors declare no potential conflict of interest related to this article

AUTHORS' CONTRIBUTIONS: Each author made significant individual contributions to this manuscript. MPGL (0000-0002-7902-9679)*: Creation of the entire research project, writing, bibliographical review, performance of data collection, supervision of the training sessions, final approval of the version of the article to be published, final draft and agreeing to accept responsibility for all the aspects of the study, to ensure that any issue relating to the integrity or accuracy of any part of it is properly investigated and resolved; $J$ LSM (0000-0002-54463153)*: Writing, performance of collections, training, data analysis, contribution to the design of the work and final draft of the article; GWPB (0000-0003-1835-4889)*: Supervision of the training sessions, data analyses and statistics; APSF (0000-0003-4111-5720)*: Performance of the training sessions and supervision of collections; ACOF (0000-0002-2505-6073)*: Final draft, data analysis and critical review of the manuscript and its intellectual content; PRCC (0000-0002-1534-3503)*: Intellectual concept, creation of the entire research project, writing, revision, data analysis, interpretation, final review of the text and final approval of the version of the manuscript to be published. *ORCID (Open Researcher and Contributor ID).

\section{REFERENCES}

1. Póvoa TIR, Jardim PCBV, Sousa ALL, Jardim TSV, de Souza WKSB, Jardim LSV. Treinamento aeróbio e resistido, qualidade de vida e capacidade funcional de hipertensas. Rev Bras Med Esporte. 2014;20(1):36-1.

2. Pescatello LS, Macdonald HV, Ash GI, Lamberti LM, FarquharWB, Arena R, et al. Assessing the existing professional exercise recommendations for hypertension: A review and recommendations for future research priorities. Mayo Clin Proc. 2015;90(6):801-6.

3. Cornelissen VA, Fagard RH, Coeckelberghs E, Vanhees L. Impact of resistance training on blood pressure and other cardiovascular risk factors: A meta-analysis of randomized, controlled trials. Hypertension. 2011;58(5):950-5

4. Forjaz CL, Santaella DF, Rezende LO, Barretto AC, Negrão CE. Effect of exercise duration on the magnitude and duration of post-exercise hypotension. Arq Bras Cardiol. 1998;70(2):99-2.
5. Bermudes AMLM, Vassallo DV, Vasquez EC, Lima EG. Monitorização ambulatorial da pressão arterial em indivíduos normotensos submetidos a duas sessões únicas de exercícios: resistido e aeróbio. Arq Bras Cardiol. 2004;82(1):57-1.

6. Shimojol GL, Dias DS, Malfitano C, Sanches IC, Llesuy, Ulloal L, Irigoyen, Angelisl K. Combined Aerobic and Resistance Exercise Training Improve Hypertension Associated With Menopause. Frotiens in Physiology. 2018; 9(1471): 1- 11.

7. Ferrari R, Umpierre D, Vogel G, Vieira PJC, Santos LP, de Mello RB, et al. Effects of concurrent and aerobic exercises on postexercise hypotension in elderly hypertensive men. Exp Gerontol. 2017;98:1-7.

8. Sharman JE, Stowasser M. Australian Association for Exercise and Sports Science Position Statement on Exercise and Hypertension. J Sci Med Sport. 2009;12(2):252-2. 
9. Vieira LGU, Queiroz ACC. Análise metodológica do treinamento de força como estratégia de controle da pressão arterial em idosos: uma revisão. Rev Bras Geriatr e Gerontol. 2013;16(4):845-4.

10. Ghadieh AS, Saab B. Evidence for exercise training in the management of hypertension in adults. Can Fam Physician. 2015;61(3):233-3.

11. Leveritt M, Abernethy PJ, Barry BK, Logan PA. Concurrent strength and endurance training. A review. Sport Med. 1999;28(6):413-6.

12. Karavirta L, Tulppo MP, Laaksonen DE, Nyman K, Laukkanen RT, Kinnunen $H$, et al. Heart rate dynamics after combined endurance and strength training in older men. Med Sci Sports Exerc. 2009;41(7):1436-7.

13. Karavirta L, Costa MD, Goldberger AL, Tulppo MP, Laaksonen DE, Nyman K, et al. Heart Rate Dynamics after Combined Strength and Endurance Training in Middle-Aged Women: Heterogeneity of Responses. PLoS One. 2013;8(8):e72664

14. Siri WE. Body composition from fluid spaces and density: analysis of methods. 1961. Nutrition. 1993;9(5):480-91; discussion 480, 492

15. Jackson AS, Pollock ML. Generalized equations for predicting body density of men. Br J Nutr. 1978;40(3):497-504

16. Santos TM dos. Fatores de potência muscular e desempenho aeróbio na corrida de 1 e 10\% de inclinação: aspectos determinantes e suas relaçōes com estímulos concorrentes. Tese de doutorado. Universidade Gama Filho. 2007.

17. Swain SD, Parrott JA, Bennett AR, Branch JD, Dowling EA. Validation of a new method for estimating VO2max based on VO2 reserve. Med Sci Sports Exerc. 2004;36(8):1421-8.

18. Campos DBP. Diretrizes do ACSM para os testes de esforço e suas prescrição / American Colegge of Sports Medicine. 9th ed. Rio de Janeiro: Guanabara; 2014.

19. Chodzko-Zajko WJ, Proctor DN, Fiatarone Singh MA, Minson CT, Nigg CR, Salem GJ, et. al. American College Sports Medicine position stand. Exercise and phisical activity for older adults. Med Sci Sport Exerc. 2009; 41(7): 1510-30.
20. Corso LML, Macdonald HV, Johnson BT, Farinatti P, Livingston J, Zaleski AL, et al. Is Concurrent Training Efficacious Antihypertensive Therapy? A Meta-Analysis. Med Sci Sports Exerc. 2016;48(12):2398-12.

21. Boutcher YN, Boutcher SH. Exercise intensity and hypertension: What's new? J Hum Hypertens 2017;31(3):157-3.

22. Borg GA. Psychophysical bases of perceived exertion. Med Sci Sports Exerc. 1982;14(5):377-5.

23. Cohen J. Statistical Power Analysis for the Behavioral Sciences. New York, NY: Routledge Academic; 1988.

24. Steiger J, Fouladi R. Noncentrality Interval Estimation and the Evaluation of Statistical Models. What if there were no significance tests? 1997. pp. 221-57.

25. dos Santos ES, Asano RY, Filho IG, Lopes NL, Panelli P, Nascimento D da C, et al. Acute and chronic cardiovascular response to 16 weeks of combined eccentric or traditional resistance and aerobic training in elderly hypertensive women: A randomized controlled trial. J Strength Cond Res. 2014;28(11):3073-84

26. eixeira L, Ritti-Dias RM, TinucciT, Mion Júnior D, Forjaz CL. Post-concurrent exercise hemodynamics and cardiac autonomic Modulation. Eur J Appl Physiol 2011, 111: 2069-2078

27. Davitt PM, Pellegrino JK, Schanzer JR, Tjionas H, Arent SM. The effects of a combined resistance training and endurance exercise program in inactive college female subjects: does order matter? Journal of Strength and Conditioning Research. 2014, V. 28, n 7, July.

28. Cadore EL, Izquierdo M, Pinto SS, Alberton CL, Pinto RS, Baroni BM, Vaz MA, Lanferdini FJ, Radaelli R, González-Izal M, Bottaro M, Kruel LF. Neuromuscular adaptations to concurrente training inthe elderly: effects of intrasession exercise sequence. 2013; 35:891-903.

29. Park S, Rink LD, Wallace JP. Accumulation of physical activity leads to a greater blood pressure reduction than a single continuous session, in prehypertension. J Hypertens. 2006 Sep;24(9):1761-70. PubMed PMID: 16915025. Epub 2006/08/18

30. Carvalho P, Barros G, Melo T, Santos P, Oliveira G, D'Amorim I. Efeito dos treinamentos aeróbio, resistido e concorrente na pressão arterial e morfologia de idosos normotensos e hipertensos. Rev Bras Atividade Física Saúde. 2013;18(3):363-3. 